\title{
Probabilistic Modelling of Hourly Rainfall Data for Development of Intensity-Duration-Frequency Relationships
}

\author{
N. Vivekanandan
}

\begin{abstract}
The rainfall Intensity-Duration-Frequency (IDF) relationship is commonly required for planning and designing of various water resources projects. The IDF relationship is a mathematical relationship between the rainfall intensity, duration and return period. This relationship is determined through statistical analysis of recorded rainfall data. In this paper, annual n-hourly maximum rainfall for different duration of 'n' such as 1-hour (hr), 2-hr, 3-hr, 6-hr, 12-hr, 18-hr, 24-hr, 48-hr and 72-hr are extracted from hourly rainfall data recorded at Hissar and Kalingapatnam; and further used for estimation of rainfall for different return periods. Order statistics approach is applied for determination of parameters of Gumbel distribution. Regional IDF relationships to estimate rainfall intensity for different return periods for Hissar and Kalingapatnam regions are developed and presented in the paper.
\end{abstract}

Keywords--- Frequency, Gumbel, Order Statistics, Rainfall, Return Period

\section{INTRODUCTION}

$\mathrm{R}$ AINFALL intensities of various frequencies and durations are the important parameter for the hydrologic design of storm sewers, culverts and many other structures, as also for rainfall-runoff models. Rainfall Frequency Analysis (RFA) is used to estimate rainfall depth at a point for a specified exceedance probability and duration. RFA is based either on annual maximum series at a site (at-site analysis) or from several sites (regional analysis). Rainfall in a region can be characterised if the intensity, duration and frequency of the diverse storms occurring at that place are known [1-3]. The available data can be used to determine the frequencies of the rainfall of different durations. The frequency-data for storms of various durations, so obtained, can be represented by IDF curves, which give a plot of average rainfall intensity $(\mathrm{mm} / \mathrm{hr})$ and duration (hr).

Raiford et al [4] have updated the existing IDF curves in the region and obtained these curves at ungauged sites throughout the region using the newly developed RFA techniques. They have also developed IDF curves and isopluvial maps for the region encompassing South Carolina,

N. Vivekanandan, Assistant Research Officer, Central Water and Power Research Station, Pune 411024, Maharashtra, India. Email:anandaan@rediffmail.com
North Carolina, and Georgia. Kim et al [5] improved the accuracy of IDF curves by using long and short duration separation technique. They derived IDF curves by using Cumulative Distribution Function (CDF) of the interesting site and multi-objective genetic algorithm. Ben-Zvi [6] proposed a procedure for basing IDF curves on partial duration series which are substantially larger than those commonly used for this purpose. He concluded that the proposed procedure superior to the current ones where the use of large samples would reduce the sensitivity of predicted intensities to sampling variations. Bara et al [7] applied the simple scaling theory to the IDF characteristics of short duration rainfall. They have concluded that the IDF relationships, which were deduced from daily rainfall, showed acceptable results in comparison with the IDF curves obtained from at-site short duration rainfall data. Okonkwo and Mbajiorgu [8] have developed IDF curves using graphical and statistical methods for South Eastern Nigeria and the results were compared. They have found that IDF curves developed from the graphical and statistical methods were very close for the lower return periods of 2-year (yr) to 10-yr and differ for higher return periods of $50-\mathrm{yr}$ to $100-\mathrm{yr}$, but the difference was not significant at 5\% level. Khaled et al [9] applied L-Moments and generalised least squares regression methods for estimation of design rainfall depths and development of IDF relationships. Rashid et al [10] applied Pearson Type-III distribution for modelling of short duration rainfall and development of IDF relationships for Sylhet City in Bangladesh.

A theoretical analysis of extreme hydrologic phenomena has led researchers to identify Gumbel distribution as a standard distribution for frequency analysis of recorded meteorological data. In addition to the above, AERB (Atomic Energy Regulatory Board) guidelines described that Order Statistics Approach (OSA) could be used for determination of estimators of Gumbel distribution though number of methods is available for parameter estimation. In this paper, an attempt has been made to estimate the extreme rainfall for different return periods for different durations of ' $\mathrm{n}$ ' such as 1-hr, 2-hr, 3-hr, 6-hr, 12-hr, 18-hr, 24-hr, 48-hr and 72-hr adopting Gumbel distribution (using OSA); and further used to develop IDF relationships for Hissar and Kalingapatnam regions. The methodology adopted in developing of IDF relationships are briefly described in the ensuing sections. 


\section{Methodology}

\section{A) Probability Distribution}

The $\mathrm{CDF}[\mathrm{F}(\mathrm{R})]$ of Gumbel distribution is given by:

$$
F(R)=e^{-e^{-\left(R_{i}-\alpha\right) / \beta}}, R_{i}, \beta>0
$$

where $\alpha$ and $\beta$ are location and scale parameters of the distribution [11]. The parameters are computed by OSA and further used to estimate rainfall $\left(\mathrm{R}_{\mathrm{T}}\right)$ for different return periods from $\mathrm{R}_{\mathrm{T}}=\alpha+\mathrm{Y}_{\mathrm{T}} \beta$, where $\mathrm{Y}_{\mathrm{T}}=-\operatorname{Ln}(-\operatorname{Ln}(1-(1 / \mathrm{T})))$. The procedures adopted in determining the OSA estimators are as follows.

OSA is based on the assumption that the set of extreme values constitutes a statistically independent series of observations. The OSA estimators of Gumbel distribution are given by:

$$
\alpha=r^{*} \alpha_{M}^{*}+r^{\prime} \alpha_{M}^{\prime} \text { and } \beta=r^{*} \beta_{M}^{*}+r^{\prime} \beta_{M}^{\prime}
$$

where $r^{*}$ and $r^{\prime}$ are proportionality factors, which can be obtained from the selected values of $\mathrm{k}, \mathrm{n}$ and $\mathrm{n}$ ' using the relations as follows:

$$
\mathrm{r}^{*}=\mathrm{kn} / \mathrm{N} \text { and } \mathrm{r}^{\prime}=\mathrm{n}^{\prime} / \mathrm{N}
$$

Here $\mathrm{N}$ is the sample size containing the basic data that are divided into $\mathrm{k}$ sub groups of $\mathrm{n}$ elements each leaving $\mathrm{n}^{\prime}$ remainders. $\alpha_{M}^{*}$ and $\beta_{M}^{*}$ are the distribution parameters of the groups, and $\alpha_{M}^{\prime}$ and $\beta_{M}^{\prime}$ are the parameters of the remainders, if any. These can be computed from the following equations:

$$
\begin{aligned}
& \alpha_{M}^{*}=(1 / k) \sum_{i=1}^{n} \alpha_{n i} S_{i} ; \alpha_{M}^{\prime}=\sum_{i=1}^{n^{\prime}} \alpha_{n^{\prime} i} R_{i} \\
& \beta_{M}^{*}=(1 / k) \sum_{i=1}^{n} \beta_{n i} S_{i} ; \beta_{M}^{\prime}=\sum_{i=1}^{n^{\prime}} \beta_{n^{\prime} i} R_{i}
\end{aligned}
$$

where $S_{i}=\sum_{i=1}^{k} R_{i j}, j=1,2,3, . ., n$. The weights $\alpha_{n i}$ and $\beta_{n i}$ are given in AERB safety guide [12].

\section{B) Procedure for Development of IDF Relationship}

IDF is a mathematical relationship between the rainfall intensity, duration, and return period. Intensity is defined as the time rate of rainfall, which is the depth per unit time $(\mathrm{mm} /$ $\mathrm{hr}$, or $\mathrm{mm} /$ day as the case may be). It can either be the instantaneous intensity or the average intensity over the duration of rainfall. Theoretically, the intensity of storm in a region varies with duration in such a way that high intensity generally corresponds to short duration, and low intensity to longer duration. IDF empirical equations are the equation that estimates the maximum rainfall intensity for different duration and return period [13-14]. The general form of empirical equation used in development of IDF relationship is expressed by:

$$
\mathrm{I}=\mathrm{A} *\left(\mathrm{~T}_{\mathrm{d}}\right)^{-\mathrm{B}}
$$

where $I$ is the rainfall intensity $(\mathrm{mm} / \mathrm{hr}), \mathrm{T}_{\mathrm{d}}$ is the rainfall duration (hr) corresponding to return period (T) and A and B are parameters. These equations indicate that for a given return period the rainfall intensity decrease with the increase in rainfall duration. Method of Least Squares (MLS) is applied to compute the parameters for the development of rainfall IDF empirical formula.

By taking logarithm on both sides of Eq, (5), we may obtain,

$\log (\mathrm{I})=\log (\mathrm{A})-\mathrm{B} \log \left(\mathrm{T}_{\mathrm{d}}\right) \quad \Rightarrow \mathrm{Y}=\mathrm{a}-\mathrm{BX} \quad$ with $\quad \mathrm{Y}=\log (\mathrm{I})$, $\mathrm{a}=\log (\mathrm{A})$ and $\mathrm{X}=\log \left(\mathrm{T}_{\mathrm{d}}\right)$

By using MLS algorithm, the parameters A and B of Eq. (5) are obtained by:

$$
\begin{aligned}
& B=\frac{\sum_{i=1}^{N} Y_{i} \sum_{i=1}^{N} X_{i}-N \sum_{i=1}^{N} X_{i} Y_{i}}{N \sum_{i=1}^{N} X_{i}^{2}-\left(\sum_{i=1}^{N} X_{i}\right)^{2}} \\
& A=\operatorname{Exp}(\bar{Y}+B \bar{X})
\end{aligned}
$$

The performance of the model is evaluated by Correlation Coefficient (CC) and expressed by:

$$
C C=\frac{\sum_{i=1}^{N}\left(I_{i}-\bar{I}\right)\left(I_{i}^{*}-\overline{I^{*}}\right)}{\sqrt{\left(\sum_{i=1}^{N}\left(I_{i}-\bar{I}\right)^{2}\right)\left(\sum_{i=1}^{N}\left(I_{i}^{*}-\overline{I^{*}}\right)^{2}\right)}}
$$

where $I_{i}$ is the recorded rainfall intensity of $i^{\text {th }}$ event, $I_{i}^{*}$ is the estimated rainfall intensity of $i^{\text {th }}$ event, $\overline{\mathrm{I}}$ is the average recorded rainfall intensity and $\overline{\mathrm{I}^{*}}$ is the average estimated rainfall intensity [15].

\section{APPLICATION}

An attempt has been made to develop IDF curves for different return periods for Hissar and Kalingapatnam regions. Hourly rainfall data [16] recorded at Hissar for the period 1970-2007 and Kalingapatnam for the period 1980-1999 are used to compute the series of annual n-hourly maximum rainfall for different durations of ' $\mathrm{n}$ ' such as 1-hr, 2-hr, 3-hr, 6-hr, 12-hr, 18-hr, 24-hr, 48-hr and 72-hr. The series were further used to compute the rainfall estimates using OSA estimators of Gumbel distribution and considered as a base values for development of IDF relationships using Eq. (5). Table 1 gives the average hourly maximum rainfall for different durations of the recorded data for the regions under study.

Table 1: Average Hourly Maximum Rainfall of Different Durations for Hissar and Kalingapatnam

\begin{tabular}{|c|c|c|c|c|c|c|c|c|c|}
\hline Region & \multicolumn{8}{|c|}{ Average hourly maximum rainfall (mm) for } \\
& \multicolumn{10}{|c|}{\begin{tabular}{c} 
different durations of 'n' such as \\
1- \\
\cline { 2 - 11 }
\end{tabular}} & $\begin{array}{c}2- \\
\mathrm{hr}\end{array}$ & $\begin{array}{c}3- \\
\mathrm{hr}\end{array}$ & $\begin{array}{c}6- \\
\mathrm{hr}\end{array}$ & $\begin{array}{c}12- \\
\mathrm{hr}\end{array}$ & $\begin{array}{c}18- \\
\mathrm{hr}\end{array}$ & $\begin{array}{c}24- \\
\mathrm{hr}\end{array}$ & $\begin{array}{c}48- \\
\mathrm{hr}\end{array}$ & $\begin{array}{c}72- \\
\mathrm{hr}\end{array}$ \\
\hline Hissar & 53.0 & 75.2 & 90.3 & 105.4 & 118.5 & 126.3 & 139.8 & 152.0 & 159.2 \\
\hline $\begin{array}{c}\text { Kalinga- } \\
\text { patnam }\end{array}$ & 50.0 & 68.4 & 80.0 & 101.0 & 119.1 & 135.3 & 146.7 & 189.6 & 215.3 \\
\hline
\end{tabular}

\section{RESUlTS AND DisCUSSIONS}

\section{A) Estimation of Rainfall using Gumbel Distribution}

By applying the procedures described above, a computer program was developed and used to fit the recorded rainfall data at Hissar and Kalingapatnam. The program computes the distributional parameters, rainfall estimates for different return 
periods from 2-yr to 1000-yr for different durations and model parameters of IDF relationships together with $\mathrm{CC}$ values. Tables 2 and 3 give the rainfall estimates for different return periods using OSA estimators of Gumbel distribution for Hissar and Kalingapatnam.

Table 2: Rainfall Estimates for Different Return Periods for Different Durations Using OSA Estimators of Gumbel Distribution for Hissar

\begin{tabular}{|r|r|r|r|r|r|r|r|r|r|}
\hline \multirow{2}{*}{$\begin{array}{c}\text { Return } \\
\text { period (yr) }\end{array}$} & \multicolumn{8}{|c|}{ Estimated rainfall (mm) for different durations of } \\
\cline { 2 - 11 } & $1-\mathrm{hr}$ & $2-\mathrm{hr}$ & $3-\mathrm{hr}$ & $6-\mathrm{hr}$ & $12-\mathrm{hr}$ & $18-\mathrm{hr}$ & $24-\mathrm{hr}$ & $48-\mathrm{hr}$ & $72-\mathrm{hr}$ \\
\hline 2 & 48.7 & 68.2 & 81.2 & 94.4 & 107.1 & 114.9 & 126.2 & 137.7 & 144.5 \\
\hline 5 & 72.9 & 105.8 & 130.6 & 155.2 & 175.3 & 184.3 & 207.2 & 226.4 & 237.3 \\
\hline 10 & 88.9 & 130.7 & 163.2 & 195.5 & 220.5 & 230.2 & 260.8 & 285.2 & 298.8 \\
\hline 25 & 109.2 & 162.2 & 204.5 & 246.5 & 277.7 & 288.2 & 328.5 & 359.4 & 376.5 \\
\hline 50 & 124.2 & 185.5 & 235.1 & 284.3 & 320.0 & 331.2 & 378.8 & 414.5 & 434.1 \\
\hline 100 & 139.1 & 208.7 & 265.5 & 321.8 & 362.1 & 373.9 & 428.7 & 469.1 & 491.3 \\
\hline 200 & 153.9 & 231.8 & 295.8 & 359.1 & 404.0 & 416.5 & 478.4 & 523.6 & 548.2 \\
\hline 500 & 173.5 & 262.3 & 335.7 & 408.4 & 459.3 & 472.6 & 544.0 & 595.4 & 623.4 \\
\hline 1000 & 188.3 & 285.3 & 365.9 & 445.7 & 501.0 & 515.1 & 593.5 & 649.7 & 680.2 \\
\hline
\end{tabular}

Table 3: Rainfall Estimates for Different Return Periods for Different Durations Using OSA Estimators of Gumbel Distribution for Kalingapatnam

\begin{tabular}{|r|r|r|r|r|r|r|r|r|r|}
\hline \multirow{2}{*}{$\begin{array}{c}\text { Return } \\
\text { period (yr) }\end{array}$} & \multicolumn{8}{|c|}{ Estimated rainfall (mm) for different durations of } \\
\cline { 2 - 11 } & $1-\mathrm{hr}$ & $2-\mathrm{hr}$ & $3-\mathrm{hr}$ & $6-\mathrm{hr}$ & $12-\mathrm{hr}$ & $18-\mathrm{hr}$ & $24-\mathrm{hr}$ & $48-\mathrm{hr}$ & $72-\mathrm{hr}$ \\
\hline 2 & 46.8 & 63.4 & 73.5 & 91.6 & 107.6 & 123.6 & 134.9 & 173.8 & 198.0 \\
\hline 5 & 61.1 & 84.7 & 97.8 & 130.0 & 158.3 & 178.4 & 194.5 & 250.0 & 277.9 \\
\hline 10 & 70.6 & 98.7 & 114.0 & 155.4 & 191.8 & 214.6 & 234.0 & 300.4 & 330.8 \\
\hline 25 & 82.6 & 116.5 & 134.3 & 187.6 & 234.1 & 260.4 & 283.8 & 364.2 & 397.7 \\
\hline 50 & 91.5 & 129.7 & 149.4 & 211.4 & 265.5 & 294.4 & 320.8 & 411.5 & 447.2 \\
\hline 100 & 100.3 & 142.7 & 164.4 & 235.0 & 296.7 & 328.1 & 357.6 & 458.4 & 496.5 \\
\hline 200 & 109.1 & 155.8 & 179.3 & 258.6 & 327.8 & 361.7 & 394.1 & 505.2 & 545.5 \\
\hline 500 & 120.7 & 173.0 & 199.0 & 289.7 & 368.7 & 406.0 & 442.4 & 566.9 & 610.2 \\
\hline 1000 & 129.4 & 186.0 & 213.9 & 313.2 & 399.7 & 439.5 & 478.9 & 613.5 & 659.1 \\
\hline
\end{tabular}

\section{B) Development of IDF Relationships}

The rainfall estimates given in Tables 2 and 3 were used to compute the average rainfall intensity for different durations and further used to develop IDF curves for different return

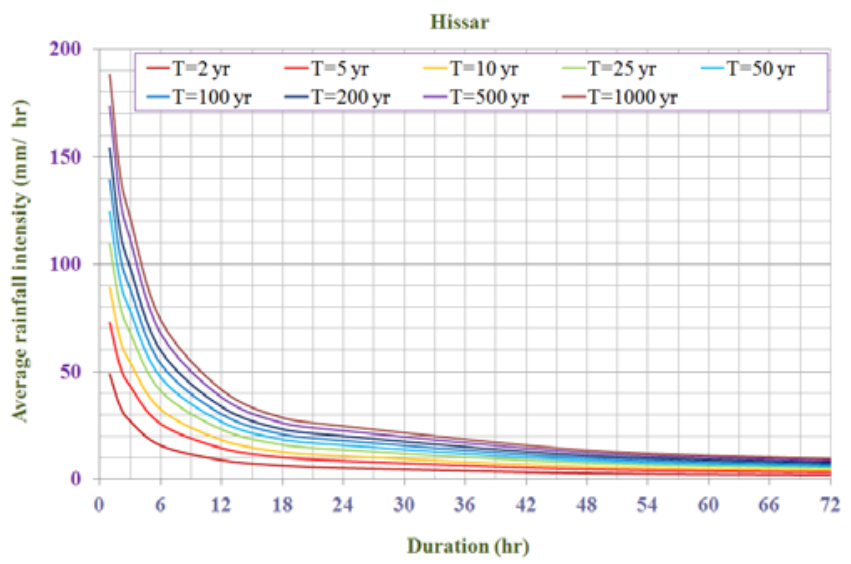

Figure 1: IDF Curves for Different Return Periods Using OSA Estimators of Gumbel Distribution for Hissar periods for Hissar and Kalingapatnam, and delineated in Figures 1 and 2.

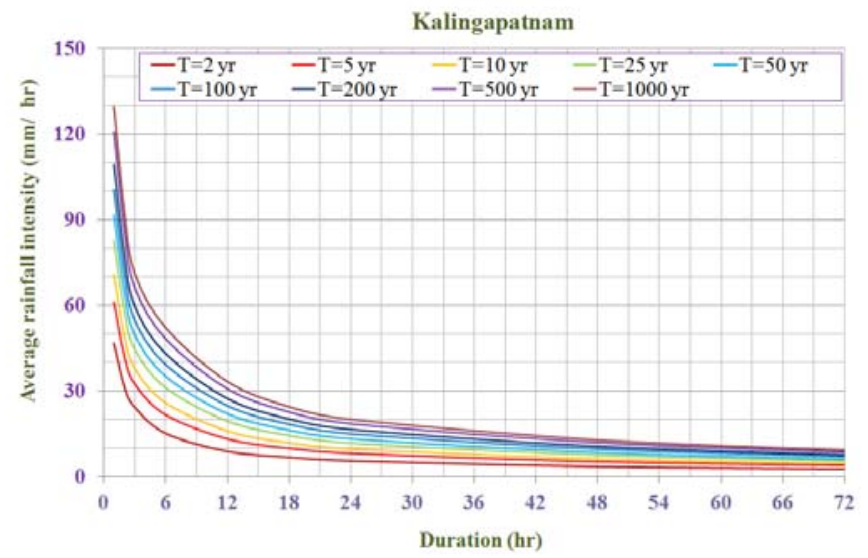

Figure 2: IDF Curves for Different Return Periods Using OSA Estimators of Gumbel Distribution for Kalingapatnam 
By using Eq. (5), IDF relationships for different return periods for Hissar and Kalingapatnam regions were developed. The parameters (A and B) of the IDF relationships were determined by MLS and given in Table 4 . The values of $\mathrm{CC}$ given by the fitted model are also given in Table 4 .

Table 4: Parameters of IDF Relationships with CC for Different Return Periods for Hissar and Kalingapatnam

\begin{tabular}{|c|c|c|c|c|c|c|}
\hline \multirow{3}{*}{$\begin{array}{c}\text { Return } \\
\text { period } \\
(\mathrm{yr})\end{array}$} & \multicolumn{3}{|c|}{ Hissar } & \multicolumn{3}{|c|}{ Kalingapatnam } \\
\hline & \multicolumn{2}{|c|}{ Parameters } & \multirow[t]{2}{*}{$\mathrm{CC}$} & \multicolumn{2}{|c|}{ Parameters } & \multirow[t]{2}{*}{$\mathrm{CC}$} \\
\hline & $\mathrm{A}$ & $\mathrm{B}$ & & $\mathrm{A}$ & $\mathrm{B}$ & \\
\hline 2 & 56.934 & 0.762 & 0.997 & 49.394 & 0.677 & 0.999 \\
\hline 5 & 87.860 & 0.744 & 0.999 & 65.578 & 0.654 & 0.999 \\
\hline 10 & 108.290 & 0.738 & 0.999 & 76.281 & 0.645 & 0.999 \\
\hline 25 & 134.170 & 0.733 & 0.999 & 89.790 & 0.636 & 0.999 \\
\hline 50 & 153.310 & 0.730 & 0.999 & 99.823 & 0.632 & 0.999 \\
\hline 100 & 172.330 & 0.728 & 0.999 & 109.730 & 0.628 & 0.999 \\
\hline 200 & 191.260 & 0.727 & 0.999 & 119.650 & 0.625 & 0.999 \\
\hline 500 & 216.260 & 0.725 & 0.999 & 132.710 & 0.622 & 0.999 \\
\hline 1000 & 235.140 & 0.724 & 0.999 & 142.560 & 0.619 & 0.999 \\
\hline
\end{tabular}

From Table 4, it may be noted that the $\mathrm{CC}$ values given by the fitted rainfall IDF relationships for Hissar and Kalingapatnam are very close to the perfect correlation value of 1 for all return periods ranging from 2-yr to 1000-yr. From the results of data analysis, it is suggested that the developed IDF relationships are better suited for estimation of rainfall intensity for different return periods for the regions under study.

\section{CONCLUSIONS}

The paper presented a computer aided procedure for modelling hourly rainfall data for Hissar and Kalingapatnam regions. The study showed that the rainfall estimates for different return periods given by Gumbel distribution (using OSA) for different durations of ' $\mathrm{n}$ ' such as 1-hr, 2-hr, 3-hr, 6hr, 12-hr, 18-hr, 24-hr, 48-hr and 72-hr OSA form the base values for estimation of average rainfall intensity for different durations for the regions under study. The results showed that $\mathrm{CC}$ values obtained from the developed IDF relationships using empirical equation of $\mathrm{I}=\mathrm{A} *\left(\mathrm{~T}_{\mathrm{d}}\right)^{-\mathrm{B}}$ are very close to 1 , which indicates the IDF relationships provide better results for both the regions. The study suggested that the IDF relationships may be useful for decision makers to estimate the rainfall intensity for any specific return period in a short time as also for planning and designing of any water resources projects in the regions specially the urban drainage management.

\section{ACKNOWLEDGEMENTS}

The author is grateful to the Director, Central Water and Power Research Station, Pune, for providing the research facilities to carry out the study. The author is thankful to India Meteorological Department, Pune, for making available the rainfall data of Hissar and Kalingapatnam regions.

\section{REFERENCES}

[1] P. Burlando and R. Rosso, "Scaling and multi-scaling models of depthduration-frequency curves for storm precipitation", Journal of Hydrology, Vol. 187, No.1-2, Pp.45-64, 1996.

[2] D. Koutsoyiannis, D. Kozonis and A. Manetas, "A mathematical framework for studying rainfall intensity- duration-frequency relationships", Journal of Hydrology, Vol. 206, No.1-2, Pp.118-135, 1998.

[3] J. Bougadis and K. Adamowski, "Scaling model of a rainfall intensityduration-frequency relationship", Hydrological Process, Vol. 20, No. 17, Pp.3747-3757, 2006.

[4] J.P. Raiford, N.M. Aziz, A.A. Khan and D.N. Powell, "Rainfall depthduration-frequency relationships for South Carolina, North Carolina, and Georgia", American Journal of Environmental Science, Vol. 3, No.2, Pp. 78-84, 2007.

[5] T. Kim, J. Shin, K. Kim and J. Heo, "Improving accuracy of IDF curves using long- and short-duration separation and multi-objective genetic algorithm", World Environmental and Water Resources Congress, Pp 1$12,2008$.

[6] A. Ben-Zvi, "Rainfall intensity-duration-frequency relationships derived from large partial duration series", Journal of Hydrology, Vol. 367, Nos. 1-2, Pp 104-114, 2009.

[7] M. Bara, L. Gaal, S. Kohnova, J. Szolgay and K. Hlavcova, "Estimation of IDF curves of extreme rainfall by simple scaling in Slovakia", Contributions to Geophysics and Geodesy Vol. 39, No. 3, Pp 187-206, 2009.

[8] G.I. Okonkwo and C.C. Mbajiorgu, "Rainfall intensity-durationfrequency analyses for South Eastern Nigeria”, Agricultural Engineering International, Manuscript, Vol. XII, 2010, No. 1304.

[9] H. Khaled, R. Ataur, G. Janice and K. George, "Design rainfall estimation for short storm durations using L-Moments and generalised least squares regression-Application to Australian Data, International Journal of Water Resources and Arid Environments, Vol. 1, No. 3, Pp. 210-218, 2011.

[10] M.M. Rashid, S.B. Faruque and J.B. Alam, "Modelling of short duration rainfall intensity duration frequency (SDRIDF) equation for Sylhet City in Bangladesh", ARPN Journal of Science and Technology, Vol. 2, No. 2, Pp. 92-95, 2012.

[11] N. Vivekanandan, "Prediction of seasonal and annual rainfall using order statistics approach of Gumbel and Frechet distributions", British Journal of Engineering and Technology, Vol. 1, No. 1, Pp. 140-151, 2012.

[12] Atomic Energy Regulatory Board (AERB), "Extreme values of meteorological parameters (Guide No. NF/SG/S-3)", 2008.

[13] L. Nhat, Y. Tachikawa and K. Takara, "Establishment of intensityduration-frequency curves for precipitation in the monsoon area of Vietnam", Annuals of Disaster Preventive Research Institute, Kyoto University, No. 49 B, 2006.

[14] R. Chowdhury, J.B. Alam, P. Das and M.A. Alam, "Short duration rainfall estimation of Sylhet:IMD and USWB method", Journal of Indian Water Works Association, Vol. 9, Nos. 3-4, Pp. 285-292, 2007.

[15] R. Acar, S. Celik and S. Senocak, "Rainfall intensity-duration-frequency model using an artificial neural network approach", Journal of Scientific \& Industrial Research, Vol. 67, No. 3, Pp. 198-202, 2008.

[16] India Meteorological Department (IMD), Report on availability of meteorological data, 2010. 